NJC

CORRECTION

View Article Online

View Journal I View Issue

\title{
Correction: Fabrication of hollow silica-nickel particles for the hydrolytic dehydrogenation of ammonia borane using rape pollen templates
}

Cite this: New J. Chem., 2017,

41,1390

Tetsuo Umegaki,* SiMin Xu and Yoshiyuki Kojima

DOI: $10.1039 / c 7 n j 90008 b$

Correction for 'Fabrication of hollow silica-nickel particles for the hydrolytic dehydrogenation of ammonia

www.rsc.org/njc

borane using rape pollen templates' by Tetsuo Umegaki et al., New J. Chem., 2017, DOI: 10.1039/c6nj03457h.

The name of the second author is incorrect in the published article. The correct author name is SiMin Xu.

The Royal Society of Chemistry apologises for these errors and any consequent inconvenience to authors and readers. 